\title{
AGROTURISMO COMO PERSPECTIVA AO PÓS-PRODUTIVISMO AGRÁRIO: UMA ANÁLISE A PARTIR DE UM ESTUDO DE CASO NO OESTE CATARINENSE
}

Jairo Marchesan ${ }^{1}$

Resumo: No município de Concórdia-SC, na última década, foi estruturada uma iniciativa de agroturismo, em paralelo às tradicionais formas de produção agropecuária em escala, fundamentado na perspectiva da agricultura multifuncional e da pluriatividade. O projeto de agroturismo Caminho da Roça, da Comunidade rural de Lajeado dos Pintos resgata a cultura dos descendentes de imigrantes italianos e é potencializada em várias atividades produtivas, culturais e sociais. $\mathrm{O}$ artigo teve como objetivo refletir teórica e praticamente sobre tal atividade turística. A análise da experiência permite constatar sua importância como nova fonte de geração de renda e oportunidade de coesão social no meio rural, se apresentando como contributo ao desenvolvimento territorial, no âmbito da agricultura familiar.

Palavras-chave: Agricultura Familiar. Agroturismo. Desenvolvimento Territorial. Pós-Produtivismo Agrário. Turismo Rural.

\section{AGRICULTURE AS A PERSPECTIVE FOR AGRICULTURAL POST- PRODUCTIVISM: AN ANALYSIS FROM A CASE STUDY IN THE WEST CATARINENSE}

Abstract: In the municipality of Concórdia-SC, in the last decade, an agrotourism initiative was structured, in parallel to the traditional forms of agricultural production on a scale, based on the perspective of multifunctional agriculture and pluriactivity. The agrotourism project Caminho da Roça, from the Rural community Lajeado dos Pintos, rescues the culture of the descendants of Italian immigrants and is enhanced in various productive, cultural and social activities. This article aimed to reflect theoretically and practically on such tourism activity. The analysis of the experience shows its importance as a new source of income generation and an opportunity for social cohesion in rural areas, presenting itself as a contribution to territorial development, within the scope of family farming.

Keywords: Family farming. Agritourism. Territorial Development. Agrarian PostProductivism. Rural tourism.

\section{AGROTURISMO COMO PERSPECTIVA AL POSPRODUCTIVISMO AGRARIO: UNA ANÁLISIS A PARTIR DE UN ESTUDIO DE CASO EN EL OESTE CATARINENSE}

Resumen: En el municipio de Concórdia-SC, en la última década, se estructura una iniciativa de agroturismo, en paralelo a las formas tradicionales de producción

\footnotetext{
1 Universidade do Contestado, Programa de Pós-Graduação em Desenvolvimento Regional, Canoinhas-SC, Brasil, jairo@unc.br https://orcid.org/ 0000-0001-9346-0185

2 Universidade do Contestado, Programa de Pós-Graduação em Desenvolvimento Regional, Canoinhas-SC, Brasil, valdirdallabrida@gmail.com https://orcid.org/0000-0003-2927-960X

3 Universidade do Contestado, Programa de Pós-Graduação em Desenvolvimento Regional, Canoinhas-SC, Brasil, letipvargas@gmail.com https://orcid.org/ 0000-0002-9186-2508
} 
agrícola a escala, basada en la perspectiva de la agricultura multifuncional y la pluriactividad. El proyecto de agroturismo Caminho da Roça, de la Comunidad rural de Lajeado dos Pintos, rescata la cultura de los descendientes de inmigrantes italianos y se potencia en diversas actividades productivas, culturales y sociales. Este artículo tuvo como objetivo reflexionar teórica y prácticamente sobre dicha actividad turística. El análisis de la experiencia muestra su importancia como una nueva fuente de generación de ingresos y una oportunidad para la cohesión social en las zonas rurales, presentándose como una contribución al desarrollo territorial, dentro del ámbito de la agricultura familiar.

Palabras clave: Agricultura familiar. Agroturismo. Desarrollo Territorial. Posproductivismo Agrário. Turismo Rural.

\section{Introdução}

O espaço rural, desde a última década do Século $X X$, em especial nos países europeus, passou por transformações significativas, dentre elas, a constituição de experiências agrícolas nas quais está presente o caráter da multifuncionalidade e pluriatividade. Tais práticas também são denominadas de pós-produtivismo agrário (ILBERY e BOWLER, 1998; ARMESTO LÓPEZ, 2005). No Brasil, o debate sobre o tema é recente e ainda são restritas as experiências nessa área. No entanto, embora tais experiências sejam crescentes, ainda são pouco impactantes para a economia e na vida das pessoas envolvidas nas atividades.

Discutir a multifuncionalidade da agricultura é admitir que a atividade agrícola desempenha outras funções, além da produção de produtos agrícolas e agroalimentares. Ou seja, as atividades rurais não se restringem apenas à produção de produtos agropecuários em escala, já que muitas experiências de atividades rurais vinculadas à estas perspectivas prestam diferentes serviços e produzem produtos diferenciados e qualificados, que contribuem na preservação e valorização dos ativos e atributos territoriais, bens naturais, tradições culturais, dentre outros.

O que se caracteriza atualmente como agricultura familiar, passa a ser reconhecido, em especial, a partir da década de 1990. A Lei 11.326 de 24/07/2006 reconhece a agricultura familiar brasileira como atividade econômica e estabelece as diretrizes para a formulação da Política Nacional da Agricultura Familiar e Empreendimentos Familiares Rurais (BRASIL, 2006). Assim, trata-se do reconhecimento desses trabalhadores como atores sociais e a produção em regime familiar como um campo de ação diferenciado.

Antes vistos apenas como os pobres do campo, os produtores de baixa renda ou os pequenos produtores, os agricultores familiares são hoje percebidos como portadores de uma outra concepção de agricultura, diferente e alternativa à agricultura latifundiária e patronal dominante no país (WANDERLEY, 2000, p. 36). 
O reconhecimento da agricultura familiar como protagonista de uma nova realidade e a construção de políticas diferenciadas para esse grupo social, que até então não tinha recebido a devida atenção, embora tivesse grande importância na produção e regulação do abastecimento dos mercados de alimentos, tiveram uma grande repercussão no cenário nacional e internacional (GRISA; SCHINEIDER, 2015).

"A agricultura familiar se afirma assim como uma categoria expressiva no meio rural brasileiro". As novas tecnologias de produção permitem a diminuição da jornada de trabalho, liberando parte dos membros da família para exercerem atividades agrícolas e não agrícolas para complementação da renda familiar (MARAFON, 2006, p. 18). Essa liberação, permite a efetivação do se passou a denominar de pluriatividade.

Schneider (2003) procura mostrar que a pluriatividade não significa uma situação totalmente nova, pois as interpretações clássicas sobre o campesinato, nas contribuições de teóricos clássicos. Por exemplo, Kautsky (1980) já vaticinava que o desenvolvimento do capitalismo na agricultura levaria a uma lenta e gradual subordinação à indústria, resultando na afirmação da superioridade técnica da grande propriedade. No entanto chamava a atenção de que esse fenômeno não levaria necessariamente à eliminação das unidades camponesas, que poderiam serem equiparadas a grande parte das propriedades agrícolas classificadas hoje como agricultura familiar. O que justificaria sua manutenção, seria a possibilidades destas propriedades desenvolverem "formas de trabalho acessório", ligadas ou não à agricultura, permitindo sua reprodução social. Na mesma linha de pensamento, Chayanov (1974) se referia às "atividades rurais não agrícolas".

De maneira geral, a concepção contemporânea de multifuncionalidade da agricultura pode ser entendida como um novo olhar sobre a agricultura familiar, a qual permite analisar a interação entre famílias rurais e territórios, considerando os modos de vida das famílias em sua integridade, e não apenas seus componentes econômicos (CAZELLA; BONNAL; MALUF, 2009). A noção incorpora a provisão, por parte dos agricultores, de bens públicos relacionados com o meio ambiente, à segurança alimentar e ao patrimônio cultural.

Já o que se convencionou chamar de pluriatividade na agricultura, refere-se a situações sociais nas quais os indivíduos que compõem uma família com domicílio rural passam a se dedicar ao exercício de um conjunto variado de atividades econômicas e produtivas, tornando-se uma estratégia de reprodução social e 
econômica. Mais precisamente, refere-se à combinação de uma ou mais formas de renda ou inserção profissional dos membros de uma mesma família (SCHNEIDER, 2003; SACCO DOS ANJOS, 2003).

Na visão de Schneider (2003, p. 23):

A pluriatividade refere-se à emergência de situações sociais em que os indivíduos que compõem uma família com domicílio rural passam a dedicarse ao exercício de um conjunto variado de atividades econômicas e produtivas, não necessariamente ligadas à agricultura e ao cultivo da terra, e cada vez menos executadas dentro da unidade de produção.

Como exemplo de atividades que apresentam potencialidades de atender à perspectiva da multifuncionalidade e/ou pluriatividade, destacam-se o agroturismo e o turismo rural. Atividades rurais vinculadas ou que atendem tais perspectivas, podem atuar paralelamente ou, também, contribuir para a superação do produtivismo rural, rumo ao pós-produtivismo. Mesmo assim, é importante alertar que tais atividades econômicas, ainda não representam ações ou intervenções transformadoras no espaço rural, pois, algumas das iniciativas pós-produtivistas ocorrem em paralelo e, muitas vezes, continuam funcionais ao modo de produção predominante.

Se tais atividades ocorrem no âmbito da agricultura familiar, no entanto, há de se considerar as limitações produtivas devido ao tamanho das propriedades rurais, normalmente, pequenas ou médias. Isso, às vezes, pode impedir a plena adoção de atividades em escala (monocultura) e de forma extensiva. É possível que essa condição obrigue a um grande número de famílias no campo buscarem outras alternativas de renda, o que os leva a desenvolverem atividades, como por exemplo, do agroturismo. De qualquer forma, pode ser uma atividade econômica diferenciada e inovadora, mesmo que seja a permitir sua reprodução social, enquanto uma das alternativas possíveis para se manterem inseridos no sistema de produção dominante. Ou seja, tanto a perspectiva da multifuncionalidade quanto da pluriatividade, são inovações contemporâneas no meio rural, na medida em que se apresentam com novas perspectivas de renda, em especial aos agricultores familiares e avalizem práticas de pós-produtivismo agrário.

Assim, o que motivou a abordagem do tema em questão neste texto foi refletir teórica e praticamente sobre quais os potenciais representados pelas atividades agroturísticas no espaço rural. Nesta direção, pretende-se analisar perspectivas de motivação e atuação de tais atividades paralelas ao sistema produtivo em curso, ou também, como possibilidades para superação do produtivismo agrário, por meio de práticas de multifuncionalidade e pluriatividade rural. 
Neste sentido, o presente texto contempla, na sua primeira parte, a revisão de literatura, fazendo referência a categorias teóricas, tais como: o turismo rural, agroturismo, produtivismo e pós-produtivismo, a multifuncionalidade e a pluriatividade no espaço rural, além de uma breve contextualização sobre a agricultura familiar. Com base nestes parâmetros teóricos, na sequência do texto, será analisada uma experiência de agroturismo, com o objetivo de caracterizar e avaliar seus limites e potenciais no espaço rural, como uma alternativa de diversificação das atividades e menor dependência de atividades tradicionais e práticas agropecuárias produtivistas.

\section{O desafio da passagem do produtivismo para o pós-produtivismo no espaço rural $^{4}$}

De maneira geral, na contemporaneidade, as atividades rurais desenvolvidas pelo setor agrícola mundial, durante muito tempo foram voltadas basicamente para produção de alimentos em crescentes quantidades. Dessas características, constituiu-se o modelo produtivista, no qual predomina a agricultura intensiva, que contou com o apoio do Estado na sua implantação e tem como principal objetivo a produção e a produtividade (LOWE et al., 1993).

Com relação a produção de produtos para a alimentação humana, a organização capitalista hegemônica mundial atua em praticamente todos os segmentos ou setores produtivos. Ou seja, desde a produção, comercialização e distribuição de alimentos. Nesta perspectiva, a organização capitalista de produção de alimentos não tem a finalidade primordial de saciar e nutrir adequadamente as pessoas. Tem, dentre outros objetivos, elevar a escala da produtividade, da hegemonia ou controle da produção, do lucro e da acumulação. Assim, os alimentos foram transformados em commodities (mercadorias).

Como ocorreu em outros países, no Brasil, o maior incentivador do sistema produtivista no espaço rural foi o Estado, situação que trouxe consequências para a agricultura, por exemplo, a inovação tecnológica com a promoção de novas cadeias produtivas voltado ao crescente mercado consumidor. No entanto, tais mudanças também favoreceram a degradação ambiental, a concentração da terra, a geração de conflitos agrários e o êxodo rural (KNICKEL, 1990).

Assim, no produtivismo, as paisagens rurais são usadas para produzir grandes quantidades de alimentos. Primeiramente, as florestas são destinadas às

\footnotetext{
${ }^{4}$ Uma abordagem introdutória sobre este tema é feita em Dallabrida e Benedetti (2016).
} 
indústrias e, posteriormente, as terras são utilizadas para a produção em escala de produtos agrícolas. Nesse modelo, os estabelecimentos agrícolas passaram a se especializar na produção de poucas variedades de produtos (monoculturas), em substituição ao sistema de diversificação (policultura). Com isso, o agricultor, agora produtor rural, passa a utilizar cada vez mais insumos industriais, produzindo para venda ao mercado, em detrimento do autoconsumo, além da substituição dos conhecimentos tradicionais pelas orientações técnicas padronizadas (DUFUMIER; COUTO, 1998).

No entanto, mudanças ocorrem no espaço rural e de produção, como novas perspectivas para o meio rural, denominadas de transição pós-produtivista. Significa possibilidades de mudança no modelo de desenvolvimento agrário dominante desde a Segunda Guerra Mundial. Neste modelo, prevalecem como principais características a qualidade e multifuncionalidade da agricultura (ILBERY e BOWLER, 1998). Com isso, o conceito de pós-produtivismo agrário incorpora as novas funções da agricultura, no que se refere à diversificação da produção e da economia rural, com atividades relacionadas principalmente ao setor terciário, resultando no que tem sido denominado de agricultura multifuncional, multidimensional e polivalente (ARMESTO LÓPEZ, 2005).

O enfoque pós-produtivista, se apresenta como perspectiva de multifuncionalidade da agricultura, como referido por Armesto López (2005), destacando a qualidade como elemento-chave, com possibilidade de instituir práticas de proteção à biodiversidade e às paisagens naturais rurais, além da geração de novos postos de trabalho como uma das características de multifuncionalidade. Ou seja, a qualidade é uma das características mais importantes no regime pós-produtivista. A busca dessa característica é impulsionada pelo aumento da demanda dos consumidores por produtos saudáveis (ILBERY e BOWLER, 1998; WILSON, 2001; ARMESTO LÓPEZ, 2005), sendo que a percepção da qualidade integra um processo no qual o consumidor exige certas características que considera relevante a um produto, além da garantia de sua origem.

Cazella e Roux (1999) também usam o termo multifuncionalidade para caracterizar o conjunto de ações relacionadas às atividades agrícolas que tratam da qualidade dos alimentos, da proteção do meio ambiente e da valorização dos diferentes tipos de territórios, além de considerarem a agricultura multifuncional um importante mecanismo no processo de vitalização rural. 
Referindo-se às origens do debate sobre a perspectiva da multifuncionalidade e/ou pluriatividade no espaço rural, Sacco dos Anjos e Caldas (2012), lembram que as motivações iniciais que serviram de incentivo e para a geração de políticas agrícolas na tentativa de superar práticas essencialmente produtivistas, além de antever um novo papel da agricultura na proteção do meio ambiente e melhoria da renda dos agricultores, visava atender ao propósito de racionalização da produção agrícola, evitando excedentes agrícolas, bem como converter o agricultor em um agente de grande capacidade, ou mais precisamente num empresário rural. Ou seja, dentre os propósitos das mudanças pretendidas, o fator econômico-empresarial tinha certo destaque.

Veja-se que, apesar das perspectivas representadas por práticas agrícolas que contemplem a perspectiva da multifuncionalidade e/ou pluriatividade, onde o agroturismo e o turismo rural são atividades já presentes em vários países, em especial da Europa, a passagem do produtivismo para o pós-produtivismo no espaço rural ainda se apresenta muito mais como uma possibilidade, do que uma realidade.

\section{Atividades agroturísticas realizadas no meio rural: tipologias e caracterização}

De maneira geral, o agroturismo no espaço rural é considerado como toda a atividade de visitação naquele espaço, proporcionando ao visitante o contato com a natureza, com as comunidades rurais, incluindo suas heranças culturais e práticas tradicionais de produção, aquisição e consumo de produtos agrícolas, dentre outros. A característica multidisciplinar e multissetorial do turismo permite a valorização dos aspectos naturais, da cultura e da atividade produtiva das comunidades rurais, estimulando, também, a recuperação e conservação da economia do território (BRASIL, 2010).

Candiotto $(2007$; 2010) destaca o debate sobre as diferentes tipologias de turismo no meio ou espaço rural, sobretudo no que tange aos conceitos de turismo no espaço/meio rural, turismo rural e agroturismo. A partir do diálogo com outros autores, Candiotto (2010) argumenta que quando se fala em turismo no espaço ou meio rural, o componente espacial é preponderante em relação às atividades desenvolvidas, de modo que qualquer atividade turística desenvolvida em um espaço que não seja urbano faz parte do turismo no espaço rural, mas não necessariamente corresponda a uma atividade de turismo rural. 
Já no que tange ao conceito de turismo rural, Candiotto (2010) sustenta sua posição em dois autores: (i) Silva e Almeida (2002), que concebem o turismo rural como uma modalidade mais restrita que o turismo no espaço rural, pois estaria reservado apenas para os casos em que as atividades rurais tradicionais (agricultura, extrativismo e pesca) desempenham algum papel na visita; (ii) Tulik (2003), reforça essa ideia ao argumentar que o turismo no espaço rural consiste em qualquer manifestação do turismo nesse meio, enquanto o turismo rural deve estar relacionado ao meio e à produção rural.

Noutra perspectiva, para Vaz (1999), o turismo rural refere-se a algo específico do modo de vida rural, classificando-o como o conjunto de atividades que compõem a vida no campo, envolvendo a experiência cotidiana no meio rural, como contato com animais e paisagens, degustação de alimentos, dentre outros. Por conseguinte, o turismo rural seria restrito às atividades que se identificam com as especificidades da vida rural, seu habitat, sua economia, sua cultura. Assim, muitas atividades que se apresentam como produtos turísticos do meio rural se caracterizam por utilizarem o meio rural apenas como base física. Segundo esse entendimento, os hotéis-fazenda ou "Spas" seriam exemplos de empreendimentos turísticos no espaço rural, que não necessariamente apresentam atrativos e equipamentos característicos do meio rural (CANDIOTTO, 2007).

Ainda nesta direção, Novaes $(2004$, p. 5) apresenta a definição de turismo rural constante nos documentos da Organização Mundial do Turismo (OMT), em que destaca o turismo como atividade complementar e integrada à agropecuária.

O Turismo Rural refere-se a lugares em funcionamento (fazendas ou plantações) que complementam seus rendimentos com algumas atividades turísticas, oferecendo geralmente alojamento, refeições e oportunidades de adquirir conhecimentos sobre as atividades agrícolas.

No que concerne ao Brasil, de acordo com o Ministério do Turismo, turismo rural é conceituado como:

[...] o conjunto de atividades turísticas desenvolvidas no meio rural, comprometido com a produção agropecuária, agregando valor a produtos e serviços, resgatando e promovendo o patrimônio cultural e natural da comunidade (BRASIL, 2010, p. 18).

Por fim, retornando às concepções de Candiotto (2010, p. 13), o conceito de agroturismo se apresenta como fundamental para a diferenciação das atividades turísticas realizadas no meio rural.

De forma geral, entende-se que o agroturismo apresenta todos os atributos do turismo rural, sobretudo pelo fato de ser uma atividade realizada no espaço rural, e ter como principais atrativos as atividades agropecuárias, os produtos para-agrícolas e o modo de vida rural. Ocorre, porém, que o 
diferencial do agroturismo em relação ao turismo rural diz respeito à participação direta e/ou indireta do turista em atividades comuns dos agricultores, como plantio, colheita, ordenha, entre outras. Nesse sentido, toda a oferta de agroturismo poderia ser classificada como turismo rural, porém nem toda a oferta de turismo rural pressupõe a existência do agroturismo.

Essa compreensão é reafirmada por Beni (2002, p. 32), que apresenta o agroturismo como: "[...] deslocamento de pessoas para espaços rurais, em roteiros programados ou espontâneos, com ou sem pernoite, para fruição dos cenários e observação, vivência e participação em atividades agropastoris". O autor ressalta que dois aspectos distinguem o agroturismo do turismo rural: (i) a produção agropastoril é a maior fonte de renda da propriedade de agroturismo, de modo que o turismo gera uma receita complementar; (ii) as próprias atividades agropastoris constituem o principal diferencial turístico, de modo que o turista pode participar ou não da rotina da propriedade.

Assim, comparando os conceitos de turismo rural e de agroturismo, segundo Candiotto (2010), a única inserção feita para o agroturismo é a vivência e participação dos turistas em atividades agropastoris. Ou seja, no agroturismo, as atividades agropecuárias, além de antecederem o turismo, são os atrativos turísticos por excelência.

Sob tais pressupostos, Candioto (2010) afirma que, assim como o turismo rural faz parte de algo mais amplo, que é o turismo no espaço rural, o agroturismo se constitui em uma submodalidade do turismo rural e propõe uma hierarquia das atividades turísticas no meio rural, conforme a figura 01.

Figura 01- Hierarquia do turismo no espaço rural

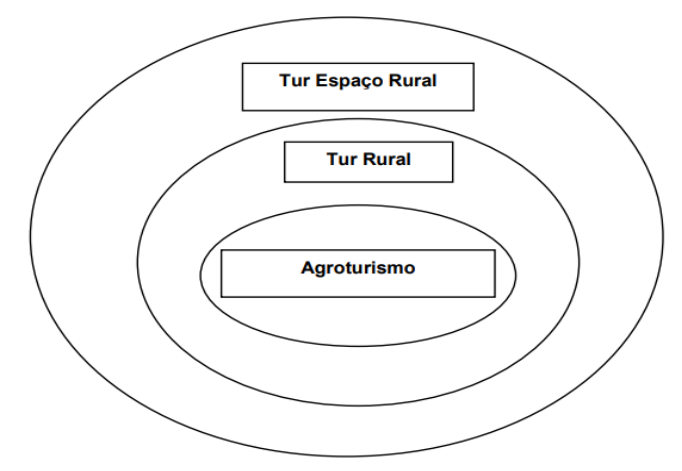

Fonte: Candiotto (2010, p. 15)

O esclarecimento sobre a diferenciação nas concepções de turismo no espaço rural, turismo rural e agroturismo, tem importância de caráter conceitual, no entanto, favorece também a análise de experiências de turismo realizadas no meio 
rural. Assim, a seguir, apresenta-se uma experiência de agroturismo no meio rural do Oeste Catarinense (Santa Catarina - Brasil).

\section{Contextualização histórica do local e do processo: o caso da Associação de Agroturismo Caminho da Roça (AACR) da Comunidade Rural de Lajeado dos Pintos - Concórdia-SC}

Historicamente, ainda nas primeiras décadas do século passado, no decorrer do processo de colonização no município de Concórdia-SC, assim como em parte do Oeste Catarinense, os agricultores familiares produziam para a subsistência familiar e o excedente era comercializado no mercado local. Mais tarde, a partir das décadas de 1960/70 do século XX, principalmente, com a constituição e consolidação dos complexos agroindustriais no referido território, os agricultores foram orientados pelo sistema produtivo em curso e do próprio Estado a produzirem produtos agrícolas e agropecuários para as agroindústrias que atendiam o crescente mercado consumidor regional e nacional. Essa mudança representou a inserção dos agricultores em práticas agrárias produtivistas.

Recentemente, no ano de 2002, o Departamento de Turismo da Prefeitura Municipal de Concórdia-SC mobilizou e viabilizou a participação de um grupo de agricultores familiares interessados a fazerem uma visita ao projeto de agroturismo desenvolvido no município de Santa Rosa de Lima, localizado no sul catarinense. $O$ município de Santa Rosa de Lima possui uma área de $203 \mathrm{~km}^{2}$ e uma população humana de aproximadamente 2.000 habitantes, com a maior população descendente da etnia alemã. Caracteriza-se, economicamente, por pequenas propriedades rurais vinculadas a agricultura familiar e policultura. Destaca-se nacionalmente pela produção de alimentos orgânicos, articulada pela Associação dos Agricultores Ecológicos das Encostas da Serra Geral (AGRECO), fundada em 1996. Assim, o referido município é considerado a capital catarinense da agroecologia.

Dentre os objetivos da Administração Pública do município de Concórdia da época, ao proporcionar uma viagem a pequenos agricultores do município para conhecer outras atividades econômicas e experiências, diferentes das tradicionais formas de produção regional, era mostrar e incentivar outras maneiras de organização e possibilidades de produção de produtos agrícolas. Ou seja, visava a mobilização dos agricultores na perspectiva de fomentar a organização e dinamização de novas atividades econômicas rurais no município de Concórdia. 
Como avaliação da iniciativa, constatou-se que tais investimentos de mobilização, de transporte, com o intuito de permitir conhecer outras experiências de produção agrícola, demonstraram a importância do Estado (municipalidade) como agente estratégico no sentido de motivar e animar os habitantes do seu território a pensarem, e, quiçá, implementarem novas relações de produção e convivência nas suas propriedades rurais.

Ainda no decorrer da visita, um grupo de agricultores familiares da comunidade rural de Lajeado dos Pintos, situada no interior do município de Concórdia, demonstrou interesse em trabalhar na perspectiva de implantar um roteiro agroturístico em sua comunidade. Mais tarde, os agricultores já articulados entre si, levaram a proposta ao Conselho Municipal de Turismo, que acatou e aprovou a proposição colocando-se à disposição para contribuir na implantação do projeto. A operacionalização do projeto contou com o apoio técnico e científico do Curso Técnico em Turismo, com ênfase no agroturismo do Serviço Nacional de Aprendizagem Comercial (SENAC), Agência de Concórdia-SC, o qual fez estudos, apresentou um diagnóstico e indicou possibilidades de implementação de um projeto de agroturismo. Assim, após várias reuniões, no dia 17 de julho de 2002, na comunidade rural de Lajeado dos Pintos, foi fundada oficialmente a Associação de Agroturismo Caminho da Roça (AACR). O Caminho da Roça constitui-se num roteiro agroturístico localizado na comunidade rural de Lajeado dos Pintos - Concórdia-SC, e está distante $8 \mathrm{~km}$ da área central da cidade. O roteiro do caminho foi lançado oficialmente no ano 2005 e envolve vários atrativos culturais.

A implantação do Projeto Caminho da Roça contou com o apoio fundamental e estratégico da Secretaria Municipal de Desenvolvimento Econômico e Turismo, do Conselho Municipal de Turismo, do SENAC - agência Concórdia-SC, e ainda da Associação Regional de Turismo Integrado das Águas do Oeste Catarinense Convention \& Visitors Bureau ${ }^{5}$.

Após a aprovação e legalização da Associação iniciou-se o processo de capacitação dos agricultores interessados, bem como da preparação, melhoria e

\footnotetext{
${ }^{5}$ É a associação de três palavras em duas línguas (inglês e francês): convention - Convenção; visitours - visitante e bureau - escritório. Portanto, escritório de visitas e negócios. A origem dos Conventions \& Visitors Bureau é norte-americana, mais precisamente da cidade de Detroit e remonta ao ano 1886. Dentre os objetivos de um Convention, tem-se a promoção de eventos e o marketing, divulgar o território, captar recursos e estimular o desenvolvimento territorial. Atualmente, Santa Catarina possui treze Conventions organizados e em funcionamento, com a perspectiva de mobilizar, articular e dinamizar as atividades turísticas regionais, gerando trabalho, renda e desenvolvimento regional.
} 
qualificação das propriedades rurais. Atualmente, o Caminho da Roça disponibiliza um conjunto de atrativos turísticos, demonstrados no Quadro 01, na sequência.

Quadro 01 - Atrativos turísticos do Caminho da Roça - Comunidade de Lajeado dos Pintos - Concórdia-SC

\begin{tabular}{|c|c|}
\hline Atrativo turístico & Atividades desenvolvidas \\
\hline Armazém Nona Thereza & $\begin{array}{l}\text { Produção de produtos orgânicos provenientes da agricultura } \\
\text { familiar, tais como: vinhos, embutidos, cachaça, açúcar } \\
\text { mascavo, licores, erva-mate, dentre outros. }\end{array}$ \\
\hline Camping Perondi & $\begin{array}{l}\text { Dispõe de uma estrutura composta por cascatas, área para } \\
\text { acampamentos, chalés, energia elétrica, campo de futebol } \\
\text { sete e restaurante. }\end{array}$ \\
\hline Nativa Plantas e Flores & $\begin{array}{l}\text { Pomar de produção e comercialização de plantas nativas } \\
\text { frutíferas e ornamentais, flores e outras. }\end{array}$ \\
\hline $\begin{array}{l}\text { Viveiro e Hidroponia } \\
\text { Dallegrave }\end{array}$ & Produção de mudas e hortaliças de diversas espécies. \\
\hline Sítio Longhi & $\begin{array}{l}\text { Espaço composto por camping, o qual dispõe de cancha para } \\
\text { corrida de cavalo, gruta, criação de ovelhas e búfalos, campo } \\
\text { de futebol sete e outros atrativos. }\end{array}$ \\
\hline $\begin{array}{l}\text { Moinho e descascador de } \\
\text { arroz da Família Belter }\end{array}$ & $\begin{array}{l}\text { Produz farinha de milho moída de forma artesanal e possui } \\
\text { um descascador de arroz. }\end{array}$ \\
\hline Pousada Pellizzaro & $\begin{array}{l}\text { Construção antiga, remodelada e adequada para uma } \\
\text { pousada rural. }\end{array}$ \\
\hline Filó de Lajeado dos $\mathrm{P}$ & I da ramilla Pellizzaro. \\
\hline
\end{tabular}

Fonte: Elaborada pelos autores a partir de documentos da AACR (2019).

Conforme apresentado acima, um dos atrativos turísticos e de maior destaque e impacto social, cultural e econômico no Caminho da Roça é o Projeto Filó. A prática do Filó ocorre de acordo com uma programação preestabelecida, como parte do roteiro agroturístico do Caminho da Roça. O Filó representa uma tradição da cultura italiana e é realizado no período noturno. Fazia parte da cultura do Norte da Itália, majoritariamente. As famílias se reuniam à noite, esporadicamente, para se encontrarem, descontrair e fortalecer relações sociais e econômicas entre vizinhos e amigos. Os motivos do encontro para o filó eram diversos, dentre os quais, destacase o fato que, devido ao frio intenso, as pessoas se reuniam para degustar comidas ou bebidas quentes. Além disso, era uma das formas de se visitarem, conversarem e divertirem-se perante as adversidades e agruras da vida cotidiana.

Quando os imigrantes italianos vieram ao Brasil, trouxeram essa cultura para o interior do Estado do Rio Grande do Sul, mais precisamente na Serra Gaúcha (Caxias do Sul, Bento Gonçalves, Garibaldi, Flores da Cunha, entre outros municípios). No Brasil, também foram surpreendidos com as adversidades do clima, dificuldades de instalação, problemas econômicos, dentre outros, o que motivou os 
agricultores a recuperar e reproduzir a prática do filó. Assim, retomaram a tradição praticada na Itália, na perspectiva de visitar um vizinho, rezar, cantar, degustar comidas e bebidas, contar histórias, praticar jogos e outros. Tradicionalmente, os homens conversavam sobre os trabalhos cotidianos, jogavam cartas, faziam negócios, dentre outros, as crianças brincavam e as mulheres conversavam e trocavam experiências domésticas. O dono da casa, normalmente oferecia alguns pratos de comidas e bebidas tradicionais, no entanto, cada convidado também poderia levar algo para socializar e degustar coletivamente.

No ano de 2004, o Projeto Filó, da Comunidade de Lajeado dos Pintos, foi registrado pelo Programa televisivo Bom dia Santa Catarina, de Joaçaba-SC, e, posteriormente, cadastrado no Festival Internacional de Audiovisual, Cultura e Turismo (FIACULT). No ano 2015 o Projeto recebeu, em Florianópolis-SC, o Prêmio Internacional ( $1^{\circ}$ lugar) no quesito "Pessoas, culturas e tradições". Esta premiação repercutiu positivamente na região, especialmente no município de Concórdia. Diante disso, a Câmara Municipal de Vereadores de Concórdia concedeu homenagem de "Menção Honrosa" ao Projeto. Assim, o Projeto Filó ampliou o seu alcance social, tornando-se uma iniciativa inédita no Estado de Santa Catarina, e, portanto, consolida-se como um dos principais produtos turísticos da região.

No caso de Concórdia, em datas preestabelecidas, no dia do Filó, um grupo de agricultores familiares e alguns adeptos à cultura italiana, vestidos com roupas de época, recebem os convidados com cantos folclóricos italianos, praticados pelos ascendentes. Uma das músicas executadas e entoadas inicialmente pelo grupo, na perspectiva de envolver a participação e interação dos convidados, é "Andemo si, andemo nó, andemo sta sera a far filó"! (Vamos sim, vamos não, vamos esta noite fazer filó). Os cantos são acompanhados por instrumentos musicais, como acordeom, violão e outros. As canções relembram a cultura e a saga dos imigrantes italianos no processo de vinda ao Brasil, sua instalação e convivência nas propriedades rurais. Além disso, os convidados, não apenas assistem, mas interagem e participam dos cantos, de um momento de reza, da virada da polenta e outras encenações alusivas ao evento. Após tais práticas culturais, os convidados degustam um jantar tipicamente da culinária italiana, regado com vinho, sucos naturais e outros acompanhamentos.

Depois do jantar, o grupo de agricultores familiares conta piadas (sfrotole) em dialeto vêneto e realizam o jogo da mora. Etimologicamente, mora significa "morra", do verbo morrer. A origem do jogo é difusa. De qualquer modo, é um jogo que faz 
parte da cultura e da tradição da região do Vêneto, Norte da Itália; foi trazida ao Brasil pelos imigrantes. Conta a cultura italiana que o jogo era realizado nas prisões como forma de superar as tristezas ou realizado pelos pastores enquanto cuidavam dos rebanhos. O jogo é realizado na língua veneta ou talian. Normalmente, o jogo é cantado e pode ser jogado em duplas ou mais componentes parceiros. $\mathrm{O}$ jogo exige muita atenção, intuição, astúcia, concentração, rápida agilidade manual e incessante e rápida pronúncia dos números. Os jogadores têm de acertar o número do conjunto de dedos da mão colocados e batidos sobre a mesa. O jogo é realizado de forma rápida, em voz alta, com entusiasmo e expressões e manifestações potencializadas em relação ao relacionamento humano. A pontuação para a vitória é convencionada previamente, e, normalmente, varia de 12 a 21 pontos. Pode haver um ou dois juízes. Ganha o jogo o jogador que acertar o número da soma de dedos sobre a mesa e acusa dizendo mio, la mora ou alla mora!

Para finalizar a atividade cultural do Filó, é servido um brodo, o qual é um prato típico da dieta alimentar da cultura italiana. Pode ser feito com carne de aves ou bovina e outros condimentos. Quando atinge o estágio em que pode ser servido, retira-se a parte sólida e serve-se o caldo quente contendo as gorduras. Normalmente, serve-se em canecas ou xícaras. O espetáculo do filó tem a duração de aproximadamente três horas.

O Projeto Filó compreende cultura, lazer, gastronomia, entretenimento e outros atrativos. Nesta direção, o Projeto Filó constitui-se num produto turístico de patrimônio cultural ${ }^{6}$ imaterial regional, consolidado como turismo de experiência. Recentemente, no ano 2014, o Projeto Caminho da Roça foi inserido no Programa SC Rural7. Portanto, faz parte de uma política pública estadual de marketing e divulgação, e, portanto, inserido no portfólio nacional de divulgação das operadoras do setor de turismo.

Nesses mais de 15 anos de consolidação do Projeto, a AACR recebeu centenas de excursões locais e regionais, compostas por milhares de turistas com

\footnotetext{
6 Constituem patrimônio cultural brasileiro os bens de natureza material e imaterial, tomados individualmente ou em conjunto, portadores de referência à identidade, à ação, à memória dos diferentes grupos formadores da sociedade brasileira, dos quais se incluem: I - as formas de expressão; II - os modos de criar, fazer e viver; III - as criações científicas, artísticas e tecnológicas; IV - as obras, objetos, documentos, edificações e demais espaços destinados às manifestações artístico-culturais; V - os conjuntos urbanos e sítios de valor histórico, paisagístico, artístico, arqueológico, paleontológico, ecológico e científico (Constituição Federal, pág. 120, 1988). Capítulo III Da Educação, da Cultura e do Desporto, Seção II da Cultura, Art. 216.

7 SC Rural é um Programa do Governo do Estado de Santa Catarina e tem como um dos objetivos preparar as propriedades rurais e inseri-las num roteiro de turismo regional integrado e que farão parte da "Rota Sabores", do Estado de Santa Catarina.
} 
caráter de lazer, técnico e científico. Assim, o Projeto Caminho da Roça é mais uma das experiências endógenas no Estado de Santa Catarina, e consolida-se como um dos roteiros de referência de agroturismo do Oeste Catarinense.

Considerando que a maior parte da população do município de Concórdia é descendente de italianos, ou então, possui relações com essa cultura, o resgate dos aspectos culturais, seja a música, gastronomia, história, tradições, dentre outros, o projeto tem a capacidade de gerar sentimentos de nostalgia e, com isso, fortalecer as relações de identidade com o território e pertencimento ao local. Sobretudo, aspira à manutenção de uma identidade comunitária, bem como contribui para reafirmar que a forma de vida vinculada ao meio rural também oferece qualidade de vida.

A história da comunidade de Lajeado dos Pintos confunde-se com o processo de colonização do município de Concórdia e da região. Foi ocupada por descendentes de imigrantes italianos, principalmente a partir das décadas de 1920 do século passado, conforme demonstra a figura 02, a seguir.

Figura 02 - Localização da Comunidade de Lajeado dos Pintos (Concórdia - SC)

MAPA DE LOCALIZAC ÃO DA COMUNIDADE DE LAJEADO DOS PINTOS, MUNICÍPIO DE

CONCÓRDIA-SC

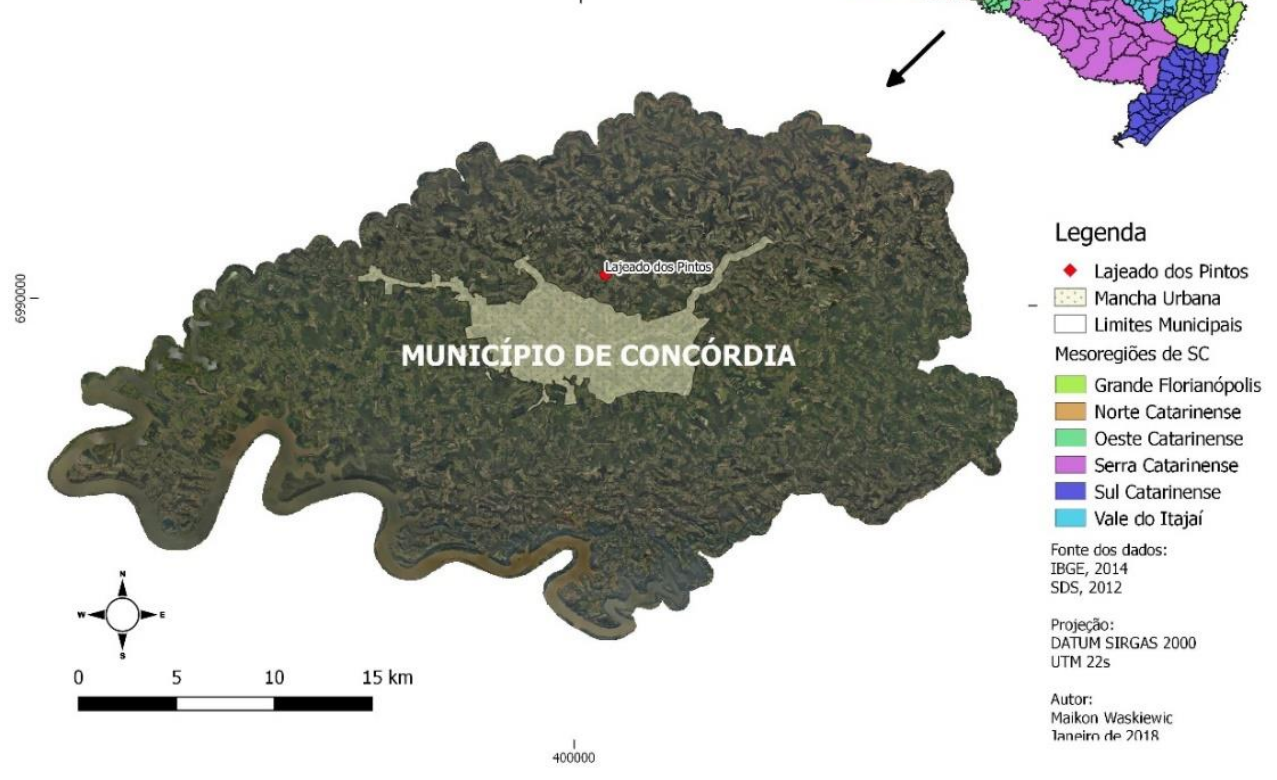

Fonte: Waskiewic (2018)

Historicamente, a principal atividade econômica foi (e ainda é) a agricultura. Tal atividade fundamenta-se na produção de produtos coloniais, como: milho, trigo, arroz, feijão, batata, mandioca e outros. Primeiramente, as famílias viviam da subsistência, e o excedente era comercializado no mercado local. A partir das 
décadas de 1960/1970 parte dos agricultores aderiu à produção agropecuária integrada às agroindústrias regionais.

Por ser uma comunidade próxima da cidade de Concórdia, de fácil acesso e a baixa rentabilidade nas atividades agropecuárias, muitos agricultores e filhos começaram a partir da década de 1990 a atuar em atividades urbanas, tanto fabris, comerciais e de serviços. Assim, muitos habitantes rurais da referida comunidade passaram a abandonar as atividades rurais e transferirem-se para a cidade. A comunidade conta com um centro comunitário onde são realizados encontros, reuniões, bailes, festas e outros. Ao lado do referido centro comunitário há uma Escola de Ensino Fundamental, uma cancha de bochas e uma igreja católica, a qual agrega religiosamente a maioria dos habitantes da comunidade.

A implementação do Projeto da Associação de Agroturismo Caminho da Roça mobilizou e despertou a Comunidade geral de Lajeado dos Pintos para a exigência do poder público de algumas demandas de infraestrutura, bem como potencializou a reativação de alguns projetos comunitários para a constituição de novos ativos territoriais locais, dentre os quais destacam-se: Projeto Artesanato (plantio de 3.500 pés de vime) que se constitui a matéria-prima para produtos artesanais; Projeto Frutas: realizado através de uma parceria com o Instituto Federal Catarinense Campus Concórdia e a Secretaria Municipal de Agricultura, e que consiste na preparação do solo e o plantio de plantas frutíferas; Projeto Hortas orgânicas; Projeto Horto das plantas medicinais; Reabertura da estrada geral até a comunidade; Projeto de pavimentação do referido trajeto. E, mais recentemente, um projeto de construção do primeiro condomínio residencial rural na referida comunidade.

Atualmente, na Comunidade de Lajeado dos Pintos há quinze famílias envolvidas diretamente na e com a Associação de Agroturismo Caminho da Roça. São famílias que atuam, produzem e comercializam os produtos agropecuários, outras recebem visitantes em suas propriedades, realizam atividades vinculadas ao agroturismo, bem como, participam ativamente da referida Associação. Destas quinze famílias, cinco delas atuam mais especificamente na produção de produtos orgânicos, os quais, são certificados pela Rede Ecovida ${ }^{8}$. As demais, atuam na produção agropecuária: suinocultura, avicultura e bovinocultura de leite.

\footnotetext{
${ }^{8}$ A Rede Ecovida de agroecologia atua nos Estados do Paraná, Santa Catarina e Rio Grande do Sul. Foi constituída no ano de 1998. Está estruturada em 27 Núcleos Regionais e abrange aproximadamente 352 municípios e envolve cerca de 4.500 famílias (REDE ECOVIDA, 2020).
} 
Outro dado referente ao Projeto é que no ano de 2019 ocorreram trinta e um eventos de filó. Ou seja, mais de dois eventos em cada mês e, em cada edição, a participação de aproximadamente setenta pessoas. Isso demonstra a demanda de interessados, que influencia diretamente no movimento socioeconômico para a Comunidade de Lajeado dos Pintos, principalmente para as famílias envolvidas.

Esses fatos apresentam o resultado do protagonismo dos agricultores e moradores da comunidade, que contribui significativamente para a potencialização e o dinamismo socioeconômico local.

\section{Breve análise da importância da atividade turística no meio rural, tendo a AACR como referência}

A atividade turística no meio rural tende a potencializar a valorização de aspectos do patrimônio cultural e natural, bem como primar pela conservação ambiental. Em função da importância política e econômica da atividade turística nos últimos dez anos, a Assembleia Geral das Nações Unidas (ONU) proclamou o ano de 2017 como o Ano Internacional do Turismo Sustentável para o Desenvolvimento. $\mathrm{Na}$ oportunidade, a Organização Mundial do Turismo (OMT) escolheu como tema prioritário, o seguinte slogan: "Turismo Sustentável: um instrumento a serviço do progresso". Tal condição demonstra a importância, os benefícios e as potencialidades que a atividade tem e pode representar não apenas economicamente, mas, sobretudo, na inclusão social, responsabilidade ambiental e bem-estar humano. Se considerarmos os temas comemorativos propostos pela ONU, entre os anos de 2010 e 2017, observa-se que os mesmos são inerentes à produção, família, alimentação, cooperação, ambiente (bens naturais) e ao turismo. Tais temáticas aproximam-se ou vinculam-se de forma direta ou indireta ao objeto em análise neste artigo.

Historicamente, o espaço rural foi associado às paisagens vegetais, disponibilidade e qualidade de bens naturais (matas, solos, águas, ar puro...) além da gastronomia diferenciada, aspectos culturais, dentre outros. Paralelamente a isso, nas últimas três décadas o espaço rural passou a ser visto por parte da população urbana vinculado aos discursos ambientalistas e associado à qualidade de vida. Assim, o turismo no meio rural passa a ser concebido como oportunidade de contato da população, em especial a que vive no espaço urbano, com os bens naturais, sejam eles a paisagem vegetal, as águas, os animais não domésticos, o ar mais puro presente no meio rural, além da apreciação dos hábitos alimentares e 
culturais e a gastronomia tradicional e/ou diferenciada vivenciada pela população rural.

Assim, a experiência da AACR, do Oeste Catarinense, vincula-se aos enfoques teóricos destacados neste artigo pode ser classificada como de agroturismo. A importância da atividade agroturística para a região em estudo é ressaltada por Guzatti (2003, p. 17), que apresenta o agroturismo como:

[...] uma ferramenta importante na construção de um desenvolvimento sustentável do espaço rural... Assim, são indicadas inúmeras possibilidades para os agricultores familiares nessa atividade: a produção de alimentos saudáveis, o processamento desses alimentos em pequenas indústrias, a preservação da natureza e da cultura, a prestação de serviços, o lazer, dentre tantas outras atividades que se multiplicam no espaço rural e consagram-se como novas oportunidades de geração de renda e de trabalho.

Desta forma, a AACR demonstra ser uma das experiências catarinenses e brasileiras, apesar de perceber-se que o agroturismo ainda é uma atividade praticada em baixa escala e, consequentemente, pouco conhecida. Nesta direção, concebe-se que a atividade agrícola sustentável, associada ao respeito e preservação das tradições culturais pode incentivar e fortalecer práticas de atividades turísticas. A recíproca também é válida, já que o agroturismo também pode potencializar a valorização do espaço rural. Consequentemente, ambas atividades se complementam e se fortalecem mutuamente. Entretanto, ressalta-se que a execução da prática do agroturismo exige organização, planejamento, atenção às demandas, resgate, manutenção e fortalecimento dos aspectos culturais e cuidado ambiental de forma contínua e sistemática.

A experiência analisada pode ser compreendida como uma atividade potencial de ser desenvolvida em comunidades rurais, especialmente àquelas baseadas na agricultura familiar diversificada, e que preservam a cultura local e os saberes da comunidade. Não se trata de ser uma atividade trabalhada em oposição, mas sim em conjunto às práticas agropecuárias tradicionalmente desenvolvidas.

Ao longo do processo de articulação, construção e consolidação do Projeto Caminho da Roça, a Associação, bem como, os agricultores e demais membros do Projeto, em suas particularidades, enfrentaram dificuldades de planejamento, projeções, ações e de operacionalidade, tanto nos aspectos individuais quanto coletivos. Tais dificuldades vincularam-se, desde a concepção e reposicionamento frente aos novos cenários e de novas formas de produção e relações de vida enquanto agricultores, da disponibilidade de tempo para reuniões, encontros, 
planejamentos, bem como, da organização ou reorganização da vida cotidiana, mudanças nas produções, divulgação, dentre outras.

Por outro lado, são reconhecidos os avanços do Projeto no sentido de reposicionamento dos agricultores vinculados a produção agrícola, da inserção em novas relações sociais, culturais e ambientais na perspectiva de se afirmarem em novas e diferenciadas atividades econômicas rurais, bem como, na viabilidade de renda e sobrevivência naquele espaço.

Evidentemente, muitos são os desafios que se apresentam, desde a manutenção da iniciativa e do grupo como agente catalisador e agregador, da necessidade de planejamento e viabilização de novos projetos, ações e intervenções individuais e coletivas, do apoio público por meio das políticas públicas para o espaço rural, além da viabilidade de manter-se nas atividades produtivas rurais que exigiram investimentos financeiros, de tempo, formação e de outros.

\section{Considerações Finais}

O Projeto Caminho da Roça, associa-se, aproxima-se e atua na perspectiva pós-produtivista. Ou seja, cultivar produtos agrícolas limpos e livres de agrotóxicos, respeitando o patrimônio natural (ambiente) e valorizando a cultura. Desta forma, o Projeto está se constituindo e se consolidando numa iniciativa política, econômica e social de referência em agroturismo regional no Oeste Catarinense.

Além disso, o Projeto desenvolvido pela Associação é entendido como um movimento local e regional diferenciado em relação ao que historicamente e tradicionalmente é desenvolvido regionalmente. Ou seja, novas relações de produção e de vida se estabelecem no espaço rural. Pode-se afirmar que está ocorrendo uma aliança entre a agricultura familiar, turismo rural e o agroturismo, os quais, resgatam culturas tradicionais, valorizam a gastronomia, preservam 0 ambiente natural e, consequentemente, contribuem com o desenvolvimento local ou bem-estar das pessoas envolvidas.

Desta forma, os agricultores familiares da comunidade rural de Lajeado dos Pintos, pautados na sua organização e como protagonistas do processo, ao recuperar, valorizar e potencializar aspectos culturais, históricos, do saber fazer tradicional, contribuem na difusão de práticas associativas e preservação ambiental, bem como promovem um novo cenário de produção agrícola, reprodução social e de vida no espaço rural no contexto regional. Com isso, o Projeto da Associação de Agroturismo Caminho da Roça - mesmo que ainda numa fase inicial -, representa 
um primeiro passo na diversificação das formas de obtenção de trabalho e renda, o que vai ao encontro da pluriatividade e/ou multifuncionalidade rural. Essa estratégia dos agricultores de complementação de renda por meio do envolvimento em atividades relacionadas ao turismo, é observada, também, em estudo realizado por Marafon (2006), no território fluminense.

Iniciativas com esse propósito exigem o apoio do Poder Público, com políticas públicas específicas. Neste sentido, no caso do município de Concórdia-SC, tem avançado, pois o Artigo 158, da Lei Orgânica do referido Município, referente ao turismo, expressa que o mesmo promoverá e incentivará o turismo como fator de desenvolvimento social e econômico, além da possibilidade de incentivar e fomentar a aplicação de recursos de empresas privadas nas áreas de turismo do município.

Portanto, conforme preconiza a legislação municipal, no caso do município de Concórdia, há amparo legal para o estímulo e investimentos públicos para atividades socioeconômicas que favoreçam avanços, como o exemplo do turismo rural ou agroturismo, desempenhando assim o Poder Público a função de articulação, indução e fomento de novas iniciativas que possam contribuir para avanços na perspectiva do pós-produtivismo agrário.

Por fim, considera-se a experiência do Projeto Filó, no município de Concórdia, um exemplo interessante e que pode ser seguido por outros municípios, considerando a importância para desencadear e/ou apoiar novas perspectivas de desenvolvimento no meio rural, em especial no âmbito da agricultura familiar, no sentido de atenuar processos de seletividade e exclusão de agricultores, provocados pelo produtivismo agrário. Dito de outro modo, quiçá esta iniciativa possa despertar novos ativos territoriais, apontar para possibilidades concretas de recuperação e potencialização de iniciativas que valorizem a cultura, gastronomia, lazer, negócios, desenvolvimento socioeconômico e qualidade de vida regional.

Permanece o desafio de estudos mais aprofundados, para identificar novas experiências similares, fazer análises comparativas na perspectiva de identificar desafios que sejam comuns, apontar indicativos de superação dos mesmos, além de destacar possibilidades para que tais experiências possam ser socializadas ou replicadas para outros espaços e contextos.

\section{REFERÊNCIAS}

ARMESTO LÓPEZ, X. A. Notas teóricas en torno al concepto de Postproductivismo Agrario. Investigaciones Geográficas, n. 36, p.137-156, 2005. 
BENI. M. C. Conceituando turismo rural, agroturismo, turismo ecológico e ecoturismo. In: BARRETTO, M.; TAMANINI, E. (Org.). Redescobrindo a ecologia no turismo. Caxias do Sul: EDUCS, 2002, p. 31-34.

BRASIL. Ministério do Turismo. Turismo Rural: orientações básicas. 2 ed. Brasília: Ministério do Turismo, 2010.

BRASIL. Lei no 11.326, de 24 de julho de 2006. Diretrizes para a formulação da Política Nacional da Agricultura Familiar e empreendimentos familiares rurais. Disponível em: <http://www.planalto.gov.br/ccivil_03/Ato2004-2006/2006/Le i/L1132 6.htm>. Acesso em: 05 de maio de 2020.

CANDIOTTO, L. Z. P. Elementos para o debate acerca do conceito de Turismo Rural. Revista Turismo em Análise, v. 21, p. 3-24, 2010.

CANDIOTTO, L. Z. P. Turismo rural na agricultura familiar: uma abordagem geográfica do Circuito Italiano de Turismo Rural, município de Colombo - PR. Tese (Doutorado) em Geografia. Florianópolis: Univ. Federal de Santa Catarina, 2007.

CAZELLA, A. A; BONNAL, P.; MALUF, R. S. Multifuncionalidade da agricultura familiar no Brasil e o enfoque da pesquisa. In: CAZELLA, A. A.; BONNAL. MALUF, R. S. (Org.). Agricultura familiar: multifuncionalidade e desenvolvimento territorial no Brasil. Rio de Janeiro: Mauad X, 2009, p. 47-70.

CAZELLA, A. A.; ROUX, B. Agribusiness em questão: a emergência da agricultura multifuncional. Estudos Sociedade e Agricultura, Rio de Janeiro, v. 13, p. 46-69, out. 1999.

CHAYANOV, A. V. La organización de la unidad económica campesina. Buenos Aires: Nueva Visión, 1974.

DALLABRIDA, V. R.; BENEDETTI, E. L. Do Produtivismo, ao Neoprodutivismo, para o PósProdutivismo: perspectivas teóricas recentes na interpretação das mudanças no espaço rural e elucidação de práticas inovadoras. Redes, v. 21, no. 3, p. 117-136, set./dez. 2016.

DUFUMIER, M.; COUTO, V. A. Neoprodutivismo. Caderno CRH, Salvador, n. 28, p. 81-112, 1998.

GRISA, C.; SCHNEIDER, S. Três gerações de políticas públicas para a agricultura familiar e formas de interação entre sociedade e Estado no Brasil. In: GRISA, C.; SCHNEIDER, S.

(Org). Políticas públicas de desenvolvimento rural no Brasil. Porto Alegre: Editora UFRGS, 2015. p. 19-50.

GUZATTI, T. C. O agroturismo como instrumento de desenvolvimento rural: sistematização e análise das estratégias utilizadas para a implantação de um programa de agroturismo nas encostas da serra geral catarinense. Dissertação (Mestrado) em Engenharia de Produção. Florianópolis: UFSC, 2003.

ILBERY, B. W.; BOWLER, I. From agricultural productivism to postproductivism. In: ILBERY, B. (Ed.). The Geography of Rural Change, Longman, Harlow, p. 57-84, 1998.

KAUTSKY, K. A questão agrária. 3. ed. Tradução de C. Iperoig. São Paulo: Proposta Editorial, 1980.

KNICKEL, K. Agricultural structural change: impact on the rural environment. Journal of Rural Studies, v.6, p. 383-393, 1990. 
LEI ORGÂNICA DO MUNICÍPIO DE CONCÓRDIA. Concórdia, 05 de abril de 1990.

LOWE, P.; MURDOCH, J.; MARSDEN, T.; MUNTON, R.; FLYNN, A. regulating the new rural spaces: the uneven development of land. Journal of Rural Studies, v. 9, p. 205-222, 1993.

MARAFON, G. J. Agricultura familiar, pluriatividade e turismo: reflexões a partir do território fluminense. CAMPO-TERRITÓRIO: Revista de Geografia Agrária, Uberlândia, v. 1, n. 1, p. 17-60, fev. 2006.

MORAES, J. L. A. Desenvolvimento Rural. In. GRIEBELER, M. P. D.; RIEDL, M. (Orgs.). Dicionário de Desenvolvimento Regional e Temas Correlatos. Porto Alegre: Conceito, 2017, p. 118-120.

NOVAES, C. A. 2004. Turismo rural e agroturismo diferenciado de turismo em espaço rural: uma proposta. In: Congresso Internacional sobre Turismo Rural e Desenvolvimento Sustentável, Anais... Joinville: IELUSC, 2004 (CD ROM).

REDE ECOVIDA. Como a rede funciona? Disponível em: <http://ecovida.org.br/>. Acesso em 20 abr 2020.

SACCO DOS ANJOS, F. Agricultura familiar, pluriatividade e desenvolvimento rural no sul do Brasil. Pelotas: UFPEL, 2003.

SACCO DOS ANJOS, F.; CALDAS, N. V. Multifuncionalidade, Turismo rural e Pluriatividade: interfaces de um debate inacabado. REDD - Revista Espaço de Diálogo e Desconexão, Araraquara, v. 5, n. 1, p. 1-23, jul/dez. 2012.

SCHNEIDER, S. Teoria Social. Agricultura Familiar e Pluriatividade. Rev. Bras. Ci. Soc., v. 18, n. 51, São Paulo, Fev./2003, p. 99-121.

VAZ, G. N. Marketing turístico: receptivo e emissivo, um roteiro estratégico para projetos mercadológicos públicos e privados. São Paulo: Pioneira, 1999.

WANDERLEY, M. N. B. A valorização da agricultura familiar e a reivindicação da ruralidade no Brasil. Desenvolvimento e Meio Ambiente, n. 2. p. 29.37.jul.Idez. 2000.

WILSON, G. A. From productivism to post-productivism... and back again? Exploring the (un)changed natural and mental landscapes of European agriculture. Transactions of the Institute of British Geographers, n. 26, p. 77-102, 2001.

\section{NOTAS DE AUTOR}

\section{CONTRIBUIÇÃO DE AUTORIA}

Jairo Marchesan - Concepção. Coleta de dados, Análise de dados, Elaboração do manuscrito, revisão e aprovação da versão final do trabalho.

Valdir Roque Dalabrida - Concepção. Análise de dados, Elaboração do manuscrito, revisão e aprovação da versão final do trabalho.

Letícia Paludo Vargas - Concepção. Análise de dados, Elaboração do manuscrito, revisão e aprovação da versão final do trabalho.

\section{FINANCIAMENTO}

Tema inserido nas atividades de investigação relacionadas à Bolsa Produtividade em Pesquisa (CNPq), do segundo autor, período 2018-2020. 


\section{APROVAÇÃO DE COMITÊ DE ÉTICA EM PESQUISA}

Não se aplica

\section{CONFLITO DE INTERESSES}

Não se aplica

\section{LICENÇA DE USO}

Este artigo está licenciado sob a Licença Creative Commons CC-BY. Com essa licença você pode compartilhar, adaptar, criar para qualquer fim, desde que atribua a autoria da obra.

\section{HISTÓRICO}

Recebido em: 09-08-2019

Aprovado em: 06-05-2020 